\title{
Research on dynamic characteristic of planetary gear system based on bond graph method
}

\author{
Xintao Zhou ${ }^{1}$, Xiayi Liu ${ }^{2}$, Longlong $\mathrm{Li}^{3}$ \\ ${ }^{1}$ School of Mechanical Engineering, Shaanxi Polytechnic Institute, Xianyang, China \\ ${ }^{2,3}$ School of Machinery and Precision Instrument Engineering, Xi' an University of Technology, \\ Xi'an, China \\ ${ }^{1}$ Corresponding author \\ E-mail: ${ }^{1} z x t 2006 s c @ 126 . c o m,{ }^{2}$ liuxy@stu.xaut.edu.cn, ${ }^{3}$ LonglongLi@stu.xaut.edu.cn
}

Received 7 October 2021; received in revised form 18 October 2021; accepted 27 October 2021 DOI https://doi.org/10.21595/vp.2021.22238

Check for updates

Copyright (C) 2021 Xintao Zhou, et al. This is an open access article distributed under the Creative Commons Attribution License, which permits unrestricted use, distribution, and reproduction in any medium, provided the original work is properly cited.

\begin{abstract}
The dynamic characteristics of planetary system directly affect the stable state of the whole transmission system. Firstly, an accurate dynamic model of planetary gear system is established by using bond graph method. Formerly, the state equation of the gear train dynamics is obtained based on the bond graph model. On this basis, the simulation model of the gear system was acquired by using the numerical simulation method, and four dynamic indexes including zero-pole diagram, Bode diagram, Nyquist diagram and Nichols diagram of the gear dynamics system were gained. Finally, the analysis results show that the accurate mathematical model is described by the bond graph method and the dynamic characteristics is comprehended of planetary gear system, while will provide a basis for the stability research of the transmission system.
\end{abstract}

Keywords: planetary gear system, bond graph method, dynamics equation of state, dynamic characteristics.

\section{Introduction}

The dynamic characteristics of planetary gear system will directly affect the healthy and stable running state of the whole transmission system [1]. Due to the existence of ulnar clearance, time-varying meshing stiffness and comprehensive transmission error in planetary gear system, the rules of dynamic characteristics of planetary gear system are extremely complex, which brings great challenges to the kinematics and dynamics design, as well as the reasonable design and accurate control of system stability $[2,3]$.

The dynamics of planetary gear transmission system, focusing on finding accurate and efficient analysis model, and exploring the dynamic response and excitation mechanism of the system $[4,5]$. The dynamic characteristics and system stability play a very important role in advanced design and fatigue analysis. However, the traditional gear train modeling method starts from the perspective of simplification and equivalence, thus some important factors affecting the system are omitted [6]. As a result, the dynamic characteristics of the gear system are much different from the actual situation, and lost its guiding significance for practical application.

\section{The bond graph model of planetary gear system}

This paper takes NGW gear train as the research object. According to the bonding diagram modeling principle, the bond graph model of planetary gear system is obtained, as shown in Fig. 1.

\section{Dynamics equation of state for gear system}

State variables $\mathbf{Y}=\left[p_{2}, q_{6}, p_{11}, p_{17}, p_{22}, p_{26}, q_{30}, p_{35}, p_{41}, p_{46}, p_{51}, p_{56}, p_{62}\right]$. According to gear train bond graph model, the state equation used to describe the motion state of the epicyclic unit was be obtained. When $\dot{p}_{17}=e_{17}, \dot{p}_{22}=e_{22}, \dot{p}_{41}=e_{41}, \dot{p}_{46}=e_{46}, \dot{p}_{51}=e_{51}, \dot{p}_{56}=e_{56}$, as shown in Eq. (1-6): 


$$
\begin{aligned}
\dot{p}_{2} & =S e_{1}-\frac{R_{7}}{\left(m_{1}\right)^{2} I_{2}} p_{2}-\frac{1}{m_{1} C_{6}} q_{6}+\frac{m_{2} R_{7}}{m_{1} I_{11}} p_{11}-\frac{R_{7}}{m_{1}} S f_{8} \\
\dot{q}_{6} & =\frac{1}{m_{1} I_{2}} p_{2}-\frac{m_{2}}{I_{11}} p_{11}+S f_{8}, \\
\dot{p}_{26} & =S e_{25}-\frac{1}{m_{3} C_{30}} q_{30}-\frac{R_{31}}{\left(m_{3}\right)^{2} I_{26}} p_{26}-\frac{R_{31}}{m_{3}} S f_{32}+\frac{m_{4} R_{31}}{m_{3} I_{35}} p_{35}, \\
\dot{q}_{30} & =\frac{1}{m_{3} I_{26}} p_{26}-\frac{m_{4}}{I_{35}} p_{35}+S f_{32}, \\
\dot{p}_{11} & =\frac{m_{2} R_{7}}{m_{1} I_{2}} p_{2}+\frac{m_{2}}{C_{6}} q_{6}-\frac{\left(m_{2}\right)^{2} R_{7}}{I_{11}} p_{11}+\frac{m_{5}\left(m_{6}\right)^{2} R_{67}}{I_{17}} p_{17}+\frac{m_{5} m_{6} m_{8} R_{67}}{I_{22}} p_{22} \\
- & \frac{m_{5} m_{6} R_{67}+m_{10} m_{11} R_{65}+m_{14} m_{15} R_{66}}{I_{35}} p_{35}+\frac{m_{10}\left(m_{11}\right)^{2} R_{65}}{I_{41}} p_{41}+\frac{m_{10} m_{11} m_{12} R_{65}}{I_{46}} p_{46} \\
+ & \frac{m_{14}\left(m_{15}\right)^{2} R_{66}}{I_{51}} p_{51}+\frac{m_{14} m_{15} m_{16} R_{66}}{I_{56}} p_{56}+m_{2} R_{7} S f_{8}+m_{5} \dot{p}_{17}+m_{10} \dot{p}_{41}+m_{14} \dot{p}_{51}, \\
\dot{p}_{35} & =-\frac{m_{6} R_{67}}{I_{17}} p_{17}-\frac{m_{8} R_{67}}{I_{22}} p_{22}+\frac{m_{4} R_{31}}{m_{3} I_{26}} p_{26}+\frac{m_{4}}{C_{30}} q_{30}+m_{4} R_{31} S f_{32}-\frac{m_{11} R_{65}}{I_{41}} p_{41} \\
& -\frac{m_{12} R_{65}}{I_{46}} p_{46}+\frac{R_{67}-\left(m_{4}\right)^{2} R_{31}+R_{65}+R_{66}}{I_{35}} p_{35}-\frac{m_{15} R_{66}}{I_{51}} p_{51}-\frac{m_{16} R_{66}}{I_{56}} p_{56},
\end{aligned}
$$

where, $m_{i}$ is the conversion coefficient of the converter, $i=1,2, \ldots, 22 ; S e_{1}$ and $S e_{25}$ are potential sources of input; $S f_{8}$ and $S f_{32}$ are steady-state transmission errors.

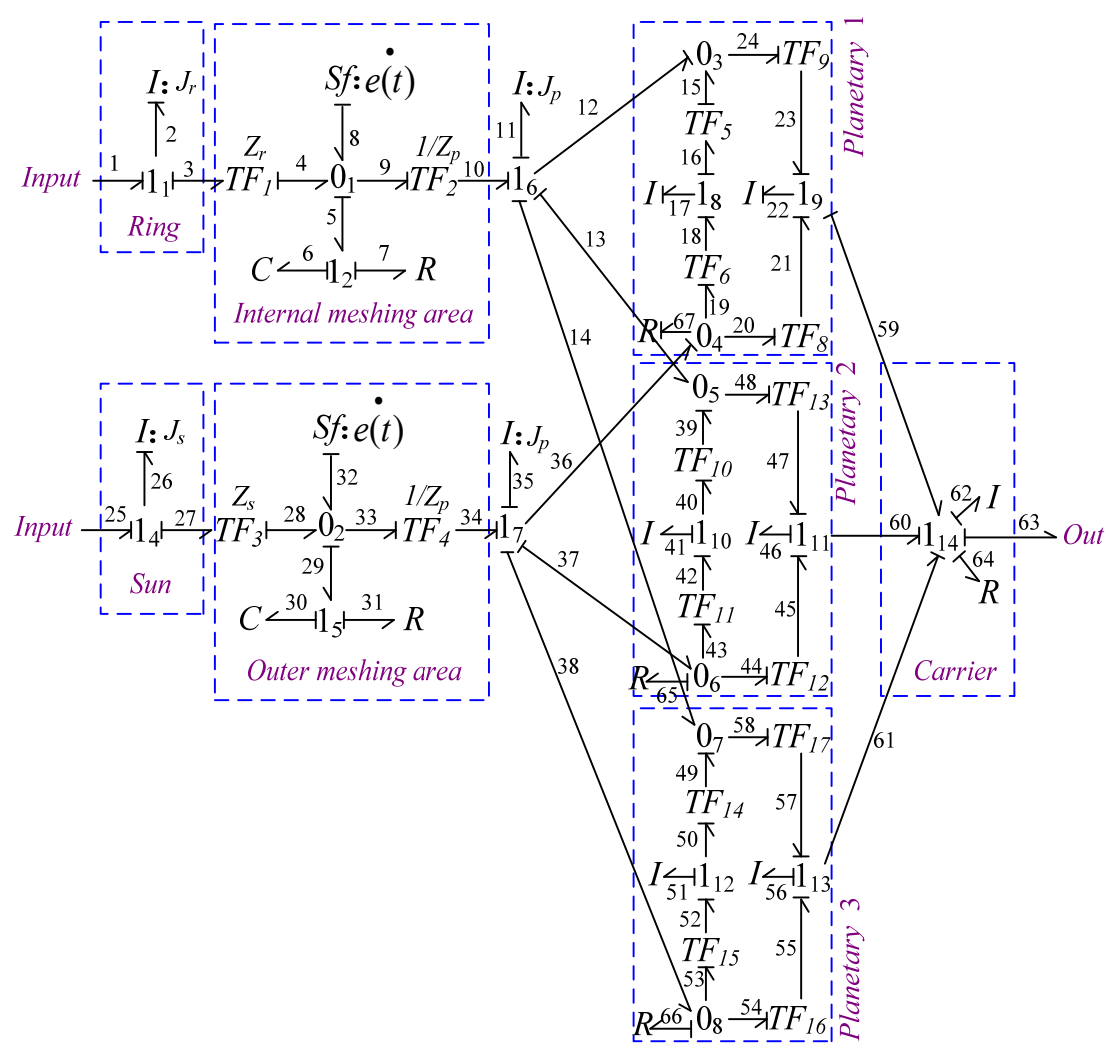

Fig. 1. The bond graph model of planetary gear system 


\section{Numerical simulation and discussion}

\subsection{Simulation condition setting}

The simulation model is shown in Fig. 2. $M S_{e 1}$ and $M S_{e 2}$ are as the input end, $M S f_{8}$ and $M S f_{32}$ are used to represent the derivatives of steady transmission errors, as show in Table 1.

Table 1. Simulation parameter

\begin{tabular}{|c|c|c|c|}
\hline $\begin{array}{c}\text { Number of } \\
\text { teeth }\end{array}$ & $Z_{s}=19, Z_{p}=31, Z_{r}=81$ & $\begin{array}{c}\text { Radius of } \\
\text { indexing circle }\end{array}$ & $\begin{array}{c}R_{s}=0.0285 \mathrm{~m}, R_{p}=0.0465 \mathrm{~m}, \\
R_{r}=0.1215 \mathrm{~m}, R_{h}=0.075 \mathrm{~m}\end{array}$ \\
\hline \multirow{3}{*}{$\begin{array}{c}\text { Moment of } \\
\text { inertia }\end{array}$} & \multirow{3}{*}{$\begin{aligned} I_{s} & =0.0015 \mathrm{Kg} \cdot \mathrm{m}^{2} \\
I_{p} & =0.0094 \mathrm{Kg} \cdot \mathrm{m}^{2} \\
I_{r} & =0.1510 \mathrm{Kg} \cdot \mathrm{m}^{2} \\
I_{h} & =0.0491 \mathrm{Kg} \cdot \mathrm{m}^{2}\end{aligned}$} & Meshing stiffness & $K g=1.8 \mathrm{e} 8 \mathrm{~N} / \mathrm{m}$ \\
\hline & & $\begin{array}{c}\text { Torsional stiffness of } \\
\text { shaft }\end{array}$ & $K s=2.0 \mathrm{e} 8 \mathrm{~N} / \mathrm{m}$ \\
\hline & & $\begin{array}{c}\text { Moment of inertia of } \\
\text { shaft }\end{array}$ & $I_{f}=0.0036 \mathrm{Kg} \cdot \mathrm{m}^{2}$ \\
\hline $\begin{array}{l}\text { Meshing } \\
\text { damping }\end{array}$ & $C_{g}=2000 \mathrm{~N} \cdot \mathrm{s} \cdot \mathrm{m}^{-1}$ & Support damping & $C_{v}=1800 \mathrm{~N} \cdot \mathrm{s} \cdot \mathrm{m}^{-1}$ \\
\hline
\end{tabular}

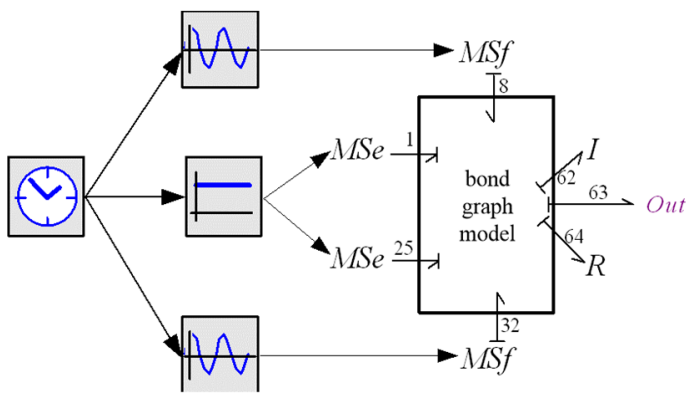

Fig. 2. Simulation model of planetary gear system

\subsection{Analysis of simulation results}

\subsubsection{Gear ring input}

It was be comprehended from Fig. 3(a) that the open loop transfer function of the system is a non-minimum phase system. The Bode diagram shown in Fig. 3(b), the phase margin $\gamma\left(\omega_{c}\right)=\infty$, and the amplitude margin $K_{g}=35.9 \mathrm{~dB}>0$ (7.09 rad $\left./ \mathrm{s}\right)$. The Nyquist diagram shown in Fig. 3(c), the open-loop frequency characteristic curve of the system does not enclose the point $\left(-1, j_{0}\right)$. Nichols diagram shown in Fig. 3(d), the vertical axis is the logarithm of amplitude and the horizontal axis is the phase Angle, which reflects the changing relationship between amplitude and phase Angle. The closed-loop system of planetary gear train is unstable under such simulated conditions.

\subsubsection{Sun gear input}

Similarly, it is be concluded from Fig. 4 that the closed loop system of the planetary gear train is unstable. 
RESEARCH ON DYNAMIC CHARACTERISTIC OF PLANETARY GEAR SYSTEM BASED ON BOND GRAPH METHOD. XINTAO ZHOU, XIAYI LIU, LONGLONG LI

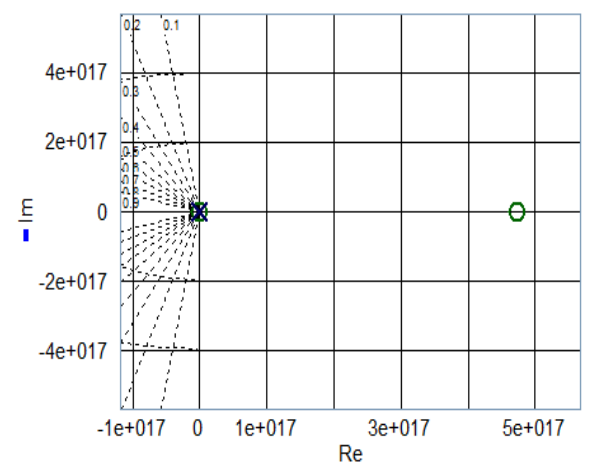

a) Pole-Zero

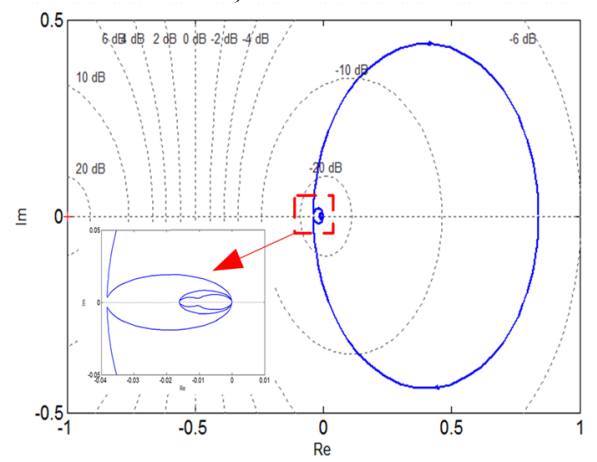

c) Nyquist

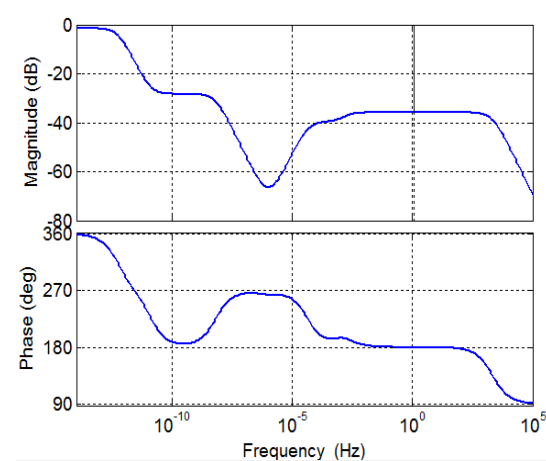

b) Bode

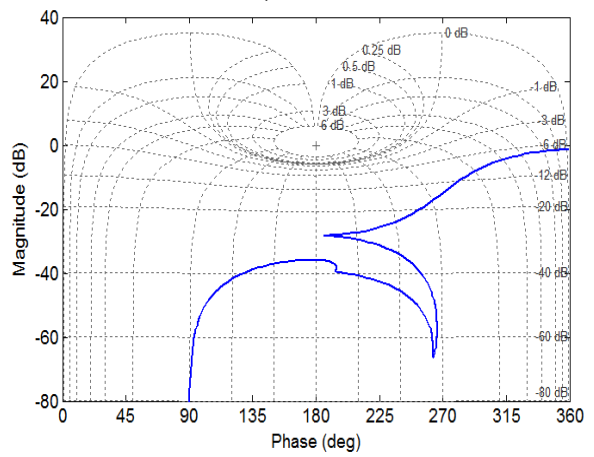

d) Nichols

Fig. 3. The stability of planetary gear system

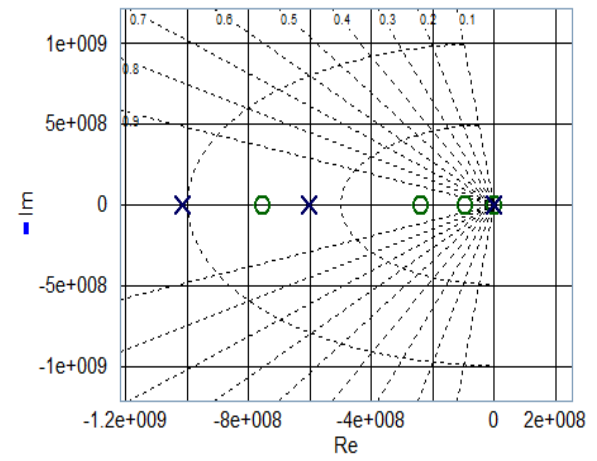

a) Pole-Zero

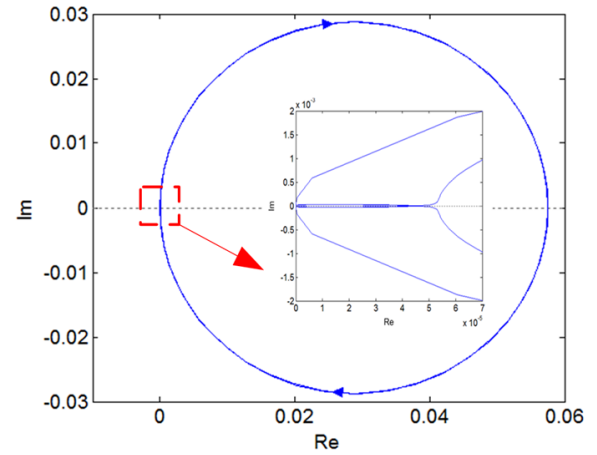

c) Nyquist

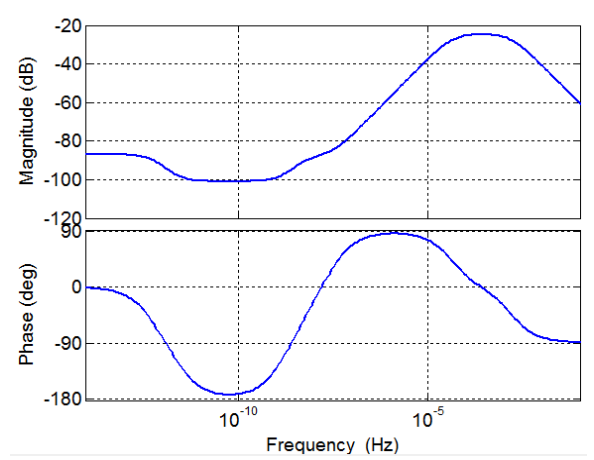

b) Bode

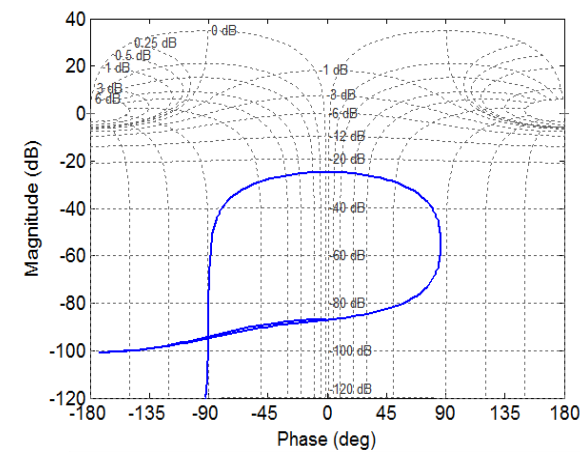

d) Nichols

Fig. 4. The stability of planetary gear system 


\section{Conclusions}

The bond graph model of the planetary gear system was established, which solved the problem that traditional modeling method could not accurately reflect the dynamic characteristics of the gear system. Then, state space and state equation of gear train dynamics are derived on the basis of bond graph model. Zero-pole diagram, Bode diagram, Nyquist diagram and Nichols diagram, are calculated by using numerical simulation method, and the dynamic rule of the gear system is reflected.

\section{Acknowledgements}

This work was supported by grants from the Scientific Research Program Funded by Shaanxi Provincial Education Department of China (No. 21JK0503) and Introduce High-level Talents to Start Scientific Research Funds by Shaanxi Polytechnic Institute of China (No. 2020-9), which were highly appreciated by the authors.

\section{References}

[1] P. Dewangan, A. Parey, A. Hammami, F. Chaari, and M. Haddar, "Dynamic characteristics of a wind turbine gearbox with amplitude modulation and gravity effect: Theoretical and experimental investigation," Mechanism and Machine Theory, Vol. 167, p. 104468, Jan. 2022, https://doi.org/10.1016/j.mechmachtheory.2021.104468

[2] L. Ryali and D. Talbot, "Dynamic load distribution of planetary gear sets subject to both internal and external excitations," Forschung im Ingenieurwesen, Jul. 2021, https://doi.org/10.1007/s10010-02100506-6

[3] H. Yang, X. Li, J. Xu, Z. Yang, and R. Chen, "Dynamic characteristics analysis of planetary gear system with internal and external excitation under turbulent wind load," Science Progress, Vol. 104, No. 3, p. 003685042110356 , Jul. 2021, https://doi.org/10.1177/00368504211035604

[4] A. Czakó, K. Řehák, A. Prokop, and V. Ranjan, "Determination of static transmission error of helical gears using finite element analysis," Journal of Measurements in Engineering, Vol. 8, No. 4, pp. 167181, Dec. 2020, https://doi.org/10.21595/jme.2020.21825

[5] J. Wang, N. Liu, H. Wang, and J. E., "Analysis of nonlinear dynamic characteristic of a planetary gear system considering tooth surface friction," Proceedings of the Institution of Mechanical Engineers, Part J: Journal of Engineering Tribology, Vol. 235, No. 11, pp. 2376-2395, Nov. 2021, https://doi.org/10.1177/1350650121991741

[6] M. Sang, K. Huang, Y. Xiong, G. Han, and Z. Cheng, "Dynamic modeling and vibration analysis of a cracked 3K-II planetary gear set for fault detection," Mechanical Sciences, Vol. 12, No. 2, pp. $847-$ 861, Sep. 2021, https://doi.org/10.5194/ms-12-847-2021 